\section{Portrayal of smoking in Nigerian online videos: a medium for tobacco advertising and promotion?}

\author{
Adegoke Oloruntoba Adelufosi, \\ Olukayode Abayomi \\ Department of Psychiatry, LAUTECH \\ Teaching Hospital, Ogbomoso, Oyo State, \\ Nigeria
}

\section{Abstract}

The Nigerian home video industry, popularly known as Nollywood is a booming industry, with increasing numbers of easily accessible online videos. The aim of this study was to analyse the contents of popular Nigerian online videos to determine the prevalence of smoking imageries and their public health implications. Using specific search terms, popular English language and indigenous Yoruba language, Nigerian home videos uploaded on YouTube in 2013 were identified and sorted based on their view counts. Data on smoking related scenes such as smoking incidents, context of tobacco use, depiction of cigarette brand, gender of smokers and film rating were collected. Of the 60 online videos whose contents were assessed in this study, 26 (43.3\%) had scenes with cigarrete smoking imageries. The mean (SD) smoking incident was 2.7 (1.6), giving an average of one smoking incident for every 26 to 27 min of film. More than half $(53.8 \%)$ of the films with tobacco use had high smoking imageries. An average of 2 characters per film smoked, mostly in association with acts of criminality or prostitution (57.7\%) and alcohol use $(57.7 \%)$. There were scenes of the main protagonists smoking in $73.1 \%$ of the films with scenes of female protagonists smoking (78.9\%) more than the male protagonists (21.1\%). Smoking imageries are common in popular Nigerian online movies. Given the wide reach of online videos, their potential to be viewed by people from different cultures and to negatively influence youngsters, it is important that smoking portrayals in online movies are controlled.

\section{Introduction}

Strict government legislations in many countries on overt advertising and promotion of tobacco products have forced many tobacco industries to look for new avenues to promote their products. The internet provides such an ideal forum for tobacco marketing because it is largely unregulated. ${ }^{1}$ Because movies are powerful means of communication and strong tool for shaping social norms, ${ }^{2}$ the tobacco industry has exploited the increasing availability of movies, which may be censored at home, but freely available for viewing on the internet, to indirectly promote tobacco products especially to youths. Tobacco imagery in movies is an important form of promotion still rarely considered by policy makers and smoking scenes still continue to permeate movies, including those rated as suitable for young people. ${ }^{2}$

According to the Global Adult Tobacco Survey, $5.6 \%$ of the Nigerian population, totalling 4.5 million adults, currently use tobacco products. ${ }^{3}$ Although the National tobacco control bill prohibits all forms of tobacco advertisements, sponsorships and sales promotions, many Nigerian home videos now feature scenes of actors smoking and even depict cigarrete brand names. The Nigerian home video industry, popularly known as Nollywood is a booming industry, described as the $2^{\text {nd }}$ biggest movie industry in the world after Indian Bollywood. ${ }^{4}$ In the last decade, accessibility to these home videos has significantly increased through their availability as online videos, freely available for viewing on the popular media website YouTube. For example, in 2012 Nigeria had the second highest YouTube viewership growth in Sub-Saharan Africa, increasing by $125 \%$ over that of 2011, while video upload increased by $50 \%$ over the same time. ${ }^{5}$ Being a popular entertainment destination, there is a potential for anonymous exploitation of YouTube by tobacco industries to reach a massive audience, particularly youngsters, by promoting and normalizing smoking. ${ }^{6}$ Smoking imageries in films influence viewers' perception and attitude towards smoking especially among youngsters and can negate effects of positive parental role modeling on smoking.? In addition, previous studies have shown that there is a strong, direct association between seeing tobacco use in films and adolescent smoking initiation. ${ }^{8,9}$

However, there is a dearth of studies on the prevalence of cigarette smoking in online versions of popular Nigerian home videos. The only available study which examined alcohol and substance use protrayals in video tapes found that tobacco was the second most portrayed substance, after alcohol. ${ }^{10}$ To our best knowledge, no study has examined the prevalence of cigarette smoking in online versions of Nigerian home videos. The aim of this study was to analyze the contents of popular Nigerian home videos uploaded on YouTube for smoking imageries prevalence and their public health implications.
Correspondence: Correspondence: Adegoke Oloruntoba Adelufosi, Department of Psychiatry, LAUTECH Teaching Hospital, 5000 Ogbomoso, Oyo State, Nigeria. Tel. +234.803 .5988054$

E-mail: ozotee@gmail.com

Conflict of interests: the authors declare no potential conflict of interests.

Key words: smoking, Nollywood, tobacco advertising.

Received for publication: 11 July 2014

Accepted for publication: 21 July 2014

This work is licensed under a Creative Commons Attribution 3.0 License (by-nc 3.0).

(OCopyright A.O. Adelufosi and O. Abayomi, 2014 Licensee PAGEPress, Italy

Healthcare in Low-resource Settings 2014; 2:4569 doi:10.4081/hls.2014.4569

\section{Materials and Methods}

This study was conducted on 20 February 2014, using specific search terms to identify popular Nigerian home videos uploaded on YouTube in 2013. Both English language and indigenous Yoruba language movies were included in the search. To identify these movies, two separate search methods were used. First, we identified English speaking movies using search terms such as Nollywood movies 2013 and Nigerian movies 2013. Indigenous Yoruba language movies were also identified using search terms such as Yoruba movies 2013, Nollywood Yoruba movies 2013 and Yoruba magic 2013. The results from these searches were sorted using the site's sort function: sort by - view count. This enabled us to identify uploaded videos most viewed.

On the assumption that few users would look at $>60$ videos, we selected 60 videos with the highest view counts, 38 from English home videos (using a cut off view count of $\geq 280,000$ ) and 22 from indigenous Yoruba language home videos (using a cut off view count of $\geq 153,000$ ). Data collected from the content analysis of the eligible home videos included: number of smoking incidents, total number of different individuals who smoked in the film, film length (in min), cigarette smoking by main protagonist(s) in the films, gender of protagonist(s), context of tobacco use, depiction of cigarette package and brand name or verbal mentioning of it, gender of cigarette smokers in the film, depiction of consequences of cigarette smoking and film rating.

We calculated the number of tobacco incidents per minute of film, defined as total incidents of tobacco use (e.g. smoking or display of cigarettes, cigarette package, ashtrays) divided by the length of film in min. ${ }^{11} \mathrm{An}$ incident is 
defined as tobacco use by an individual in a single scene, no matter the number of times the camera cuts back and forth between a smoker and a non-smoker in the scene. Thus, a 52 min film with 6 incidents of smoking will have a smoking incident per minute of 0.12 or approximately one incident for every 8 to $9 \mathrm{~min}$ of film. Home videos with tobacco use were further subdivided into those with low use (films with $\leq 2$ smoking incidents) and those with high use (>2 smoking incidents). Data were analysed using Statistical Package for Social Sciences (SPSS) version 16 (SPSS, Chicago, IL, USA) and presented using a frequency distribution table.

\section{Results}

Overall, the length included videos ranged from 38 to 104 min with view counts that ranged from 143,366 to $6,830,366$. Of the 60 online videos whose contents were assessed in this study, 26 (43.3\%) had scenes with cigarrete smoking imageries. Among films with smoking imageries, the mean (SD) film length was 72.35 (15.9) while the mean (SD) smoking incident was 2.7 (1.6), giving an average of one smoking incident for every 26 to $27 \mathrm{~min}$ of film. More than half (53.8\%) of the films with tobacco use had high smoking imageries. An average of 2 characters per film smoked, mostly in scenes depicting criminality or prostitution (57.7\%) and alcohol use $(57.7 \%)$. There were scenes of the main protagonists smoking in $73.1 \%$ of the films with scenes of female protagonists smoking (78.9\%) more than the male protagonists (21.1\%) (Table 1).

\section{Discussion}

This study examined the prevalence and extent of tobacco portrayals in an online sample of Nigerian English and indigenous Yoruba speaking videos. The high proportion of movies, almost half of the total movies analyzed in this study, depicting tobacco imagery creates some concern. Previous studies have demonstrated a direct relationship between frequency of exposures to smoking imageries in movies and the likelihood of initiating smoking. ${ }^{12}$ The public health risk of such imageries becomes obvious when one considers the potential wide reach of online videos as well as their long shelf life on the internet.

The relationship between the entertainment and tobacco industries is mutually beneficial with the latter providing monetary or material support to film producers in exchange for using or depicting tobacco products in their films. ${ }^{13}$ While firm conclusions cannot be drawn based on the findings of this study alone, the high rate of tobacco imageries and even brand name depiction by many of the movies, raise the possibility of paid product advertisement by the tobacco industry. This subtle but powerful medium of advertisement reflects loopholes in existing legislation on tobacco advertisement in Nigeria and represents at a global level, the unrelenting efforts by tobacco industries to promote the social acceptability and desirability of tobacco use. ${ }^{13}$

According to the definitions in Article 1 of the World Health Organization Framework Convention on Tobacco Control (WHO FCTC), a comprehensive ban on all tobacco advertising, promotion and sponsorship applies to all forms of commercial communication, recommendation or action and all forms of contribution to any event, activity or individual with the aim, effect or likely effect of promoting a tobacco product or tobacco use either directly or indirectly. ${ }^{14}$ This definition would imply that various forms of smoking imagery in movies would be included as part of the comprehensive ban called for by the WHO FCTC, a bill which was also ratified by Nigeria in 2005 .

A higher proportion of cigarette smokers in the movies examined were women compared to men. This could be a reflection of changes in cultural values and societal perception of the feminine role, resulting from an increasing influence of westernization and female empowerment. ${ }^{15}$ In the last few decades Nigeria has witnessed an increasing struggle for gender equality in a society where the female gender is often at a disadvantage when compared to their male counterparts. ${ }^{16}$ Adopting lifestyle habits such as smoking that are traditionally associated with males and once considered a social taboo among women, may be an indirect way of asserting gender equality. In addition, tobacco industries have increasingly targeted women specifically in their marketing, promoting smoking as a symbol of emancipation. ${ }^{17}$

Smoking imageries in movies encourage youngsters to smoke and is a potent method for recruiting new smokers. ${ }^{8,18}$ The desire to smoke can further be reinforced when popular actors/actresses, whom youths look up to as role models for socialization, smoke in movies. ${ }^{19}$ In this study, popular actors, mostly females, were protagonists in the movies examined, and no negative consequences of their smoking habits were depicted by any of the movies. In addition, only 3 of the 27 movies depicting smoking sceneries were rated (for general viewers), indicating a need for closer monitoring by the appropriate regulatory body. In fact, $57.7 \%$ of movies depicting cigarette smoking showed its use along with alcohol, mostly in social settings and also in connection with social vices such as prostitution and other criminal behaviors. This finding is simi lar to that obtained in previous studies. ${ }^{20}$ None of the movies in this study depicted any negative consequences among characters who smoked cigarette, thereby giving a misleading impression that cigarette smoking is harmless. Similar observations were made in a previous study in which $99.6 \%$ of film characters

Table 1. Smoking variables in online films.

\begin{tabular}{|c|c|c|c|}
\hline \multirow[t]{2}{*}{ Variable } & & \multicolumn{2}{|c|}{ Frequency } \\
\hline & & n & $\%$ \\
\hline \multirow[t]{2}{*}{ Smoking incidents category } & Low & 14 & 53.8 \\
\hline & High & 12 & 46.2 \\
\hline \multirow[t]{2}{*}{ Main protagonist smoking } & Yes & 19 & 73.1 \\
\hline & No & 7 & 26.9 \\
\hline \multirow[t]{2}{*}{ Gender of main protagonist* } & Male & 4 & 21.1 \\
\hline & Female & 15 & 78.9 \\
\hline \multirow[t]{2}{*}{ Smoking context } & Socializing/partying & 11 & 42.3 \\
\hline & Criminality/prostitution & 15 & 57.7 \\
\hline \multirow[t]{2}{*}{ Associated alcohol use } & Yes & 15 & 57.7 \\
\hline & No & 11 & 42.3 \\
\hline \multirow[t]{2}{*}{ Cigarette brand name depicted } & Yes & 13 & 50 \\
\hline & No & 13 & 50 \\
\hline \multirow[t]{3}{*}{ Gender of smokers } & Males only & 6 & 23.1 \\
\hline & Females only & 12 & 46.2 \\
\hline & Both gender & 8 & 30.8 \\
\hline \multicolumn{4}{|c|}{ Smoking consequences depicted in film? } \\
\hline & Yes & 0 & 0 \\
\hline & No & 26 & 100 \\
\hline \multirow[t]{2}{*}{ Film rating indicated? } & Yes & 3 & 11.5 \\
\hline & No & 23 & 88.5 \\
\hline
\end{tabular}

*Nineteen of the 26 films examined had imageries of main protagonist(s) smoking. 
who smoked on the screen suffered no life threatening consequences, making them seem invincible and belying tobacco's role as a leading cause of preventable death. ${ }^{21}$

\section{Conclusions}

Given the wide reach of online videos and their potential to be viewed by people from different cultures, it is important that tobacco advertisements be limited in online movies. Some suggested recommendations by the World Health Organization include formulating policies that will motivate change in film industries' behavior so that harmful contents are reduced and to encourage disclosures by film makers who received any form of support from tobacco industries. ${ }^{22}$ On a global level, YouTube could be urged to adopt a rating system for smoking in videos, with those not meeting the recommended guidelines for a general audience subsequently banned from the site. ${ }^{6}$ There is need for a strong partnership between the Nigerian movie industry regulators and the Nigerian government, for an effective and comprehensive ban on all indirect forms of tobacco promotion and advertisement.

\section{References}

1. Elkin L, Thomson G, Wilson N. Connecting world youth with tobacco brands: YouTube and the internet policy vacuum on Web 2.0. Tob Control 2010;19:361-6.

2. Zolty B. Smoke-free movies: an important component of a comprehensive ban on tobacco advertising, promotion and sponsorship. Eur J Public Health 2012;22:168.

3 . World Health Organization. The government of Nigeria releases the first ever global adult tobacco survey (GATS) report.
Geneva: World Health Organization ed.; 2013. Available from: http://www.afro.who. int/en/nigeria/press-materials/item/5719the-government-of-nigeria-releases-thefirst-ever-global-adult-tobacco-surveygats-report-in-the-african-region.html

4. United Nations. Nigeria surpasses Hollywood as world's second largest film producer. New York: United Nations; 2009. Available from: http://www.un.org/ apps/news/story.asp?NewsID=30707\#.U3B CaKIvDQo

5. This Day Live. Nigeria records 2nd highest YouTube figures in Sub Saharan Africa in 2012. Apapa: This Day Live ed.; 2012. Available from: http://www.thisdaylive. com/articles/nigeria-records-2nd-highestyoutube-figures-in-sub-saharan-africa-in2012/140955/

6. Freeman B, Chapman S. Is "YouTube" telling or sellingyou something? Tobacco content on the YouTube video-sharing website. Tob Control 2007;16:207-10.

7. Sargent JD, Dalton MA, Beach ML, et al. Viewing tobacco use in movies: does it shape attitudes that mediate adolescent smoking? Am J Prev Med 2002;22:137-45.

8. Sargent JD, Beach ML, Dalton MA. Effect of seeing tobacco use in films on trying smoking among adolescents: cross sectional study. Brit Med J 2001;323:1-6.

9. Charlesworth A, Glantz SA. Smoking in the movies increases adolescent smoking: a review. Paediatrics 2005;116:1516-28.

10. Aina OF, Olorunshola DA. Alcohol and substance use portrayals in Nigerian video tapes: an analysis of 479 films and implications for public drug education. Int $Q$ Community Health Educ 2008;28:63-71.

11. Mekemson C, Glik D, Titus K, et al. Tobacco use in popular movies during the past decade. Tob Control 2004;13:400-2.

12. Laugesen M, Scragg R, Wellman RJ, DiFranza JR. R-rated film viewing and adolescent smoking. Prev Med 2007;45:454-9.
13. Mekemson C, Glantz SA. How the tobacco industry built its relationship with Hollywood. Tob Control 2002;11(Suppl.1): 81-91.

14. World Health Organization. Guidelines for implementation of article 13 of the WHO Framework Convention on Tobacco Control (Tobacco advertising, promotion and sponsorship). Geneva: World Health Organization; 2011. Available from: http://www.who. int/fctc/guidelines/article_13.pdf?ua=1

15. Adesina OS. The negative impact of globalization on Nigeria. Int J Humanit Soc Sci 2012;2193-201. Available from: http://www. ijhssnet.com/journals/Nol_2_No_15_Augu st_2012/24.pdf

16. Oyekanmi FD. Institutionalization of gender inequality in Nigeria: implications for the advancement of women. Population Rev 2005;44:56-71.

17. Amos A, Haglund M. From social taboo to "torch of freedom": the marketing of cigarettes to women. Tob Control 2000;9:3-8.

18. Watson NA, Clarkson JP, Donovan RJ, Giles-Corti B. Filthy or fashionable? Young people's perceptions of smoking in the media. Health Educ Res 2003;18;5:554-67.

19. Tickle J, Sargent J, Dalton M, et al. Favourite movie stars, their tobacco use in contemporary movies, and its association with adolescent smoking. Tob Control 2001;10:16-22.

20. Dalton MA, Tickle JJ, Sargent JD, et al. The incidence and content of tobacco use in popular movies from 1988 to 1997 . Prev Med 2002;34:516-23.

21. Dozier DM, Lauzen MM, Day CA, et al. Leaders and elites: portrayals of smoking in popular films. Tob Control 2005;14:7-9.

22. World Health Organization. Smoke-free movies: from evidence to action. Geneva: World Health Organization; 2011. Available from: http://whqlibdoc.who.int/publications/2011/9789241502399_eng.pdf?ua=1 